\title{
THE CITY OF OSTRAVA (CZECH REPUBLIC): A SUSTAINABILITY ASSESSMENT BASED ON VITALITY
}

\author{
MARTIN NEDVĚD ${ }^{1 *} \&$ MARTINA PEŘINKOVÁ ${ }^{2}$ \\ ${ }^{1} V S \breve{B}$ - Technical Unversity Of Ostrava, Czech Republic \\ ${ }^{2}$ Faculty of Civil Engineering, Department of Architecture, Technical University of Ostrava, Czech Republic
}

\begin{abstract}
The largest post-industrial agglomeration in the Czech Republic is the Ostrava-Karviná settlement region covering the southern part of the Upper Silesian Coal Basin. The polycentric model of settlement, which is the consequence of mining and its accompanying phenomena (colonization, contamination, undermining, transport), comprises several medium-sized cities and one regional metropolis - Ostrava. Ostrava is a dominant regional centre which integrates economic and financial, intellectual and educational, cultural and social, as well as administrative functions. All of these functions need to be continuously formulated and formed, but, in particular, they must flexibly react to the current situation. Therefore, it is necessary to do not only short-term, but also long-term planning led by a leading idea (vision, theme) to achieve the most effective model of an urban and regional unit. The transformation which Ostrava has been undergoing since the 1990s means that the city is being transformed substantially from both the social-economic and urbanistic point of view. It is appropriate to solve the problems connected with the changes systematically, not to take only the current state into consideration, but to focus also on the long-term orientation of the settlement and the entire agglomeration. Finding an optimum solution, or a "motive" which would unite ideas for the effective development, transformation and forming of the city is a demanding process, but quite essential for the agglomeration to survive.
\end{abstract}

Keywords: ostrava, post-industrial city, urbanism, sustanability, vitality.

\section{INTRODUCTION}

The oldest preserved settlement in the area of today's Ostrava was on the Landek hill above the confluence of the Odra and the Ostravice. Archaeological findings prove that a settlement was there as early as the Old Stone Age, as well as incidental use of the black coal from the emerging coal beds as a fuel. The Holasice fort was built on Landek in the 8th century and a stone Premyslide castle in the 13th century. The oldest written documents state the existence of Polish (today's Silesian) Ostrava in 1229 and Moravská Ostrava in 1267 (which was granted city status in the following decade). In the Middle Ages and a large period of the Modern Times, Moravská Ostrava was only a small mercantile town on the trade route between the important regional centres of Opava and Těšín. A substantial change in this paradigm was made by the discovery of coal (officially recorded in 1763) and the subsequent commencement of its regular mining in 1787 [1].

Coal mining was followed by the construction of Vítkovice Ironworks, a railway line (North Ferdinand's Railway) and a rapid growth of the agglomeration. In the period before the establishment of the ironworks, the population of Moravská Ostrava was about 1,750; in 1910 , it was as many as 36,000 and just before the reduction in mining in the 1990s the population culminated at 321,000. In his book Cities and People (GIROUARD, 1985) Mark Girouard puts in contrast the cities of Babel and Jerusalem types, where Babel is a metaphor of large, rich and sinful cities, "prostitutes, mothers of fornication and ugliness of the Earth"1, and by Jerusalem he designates ideal and well-ordered cities. 


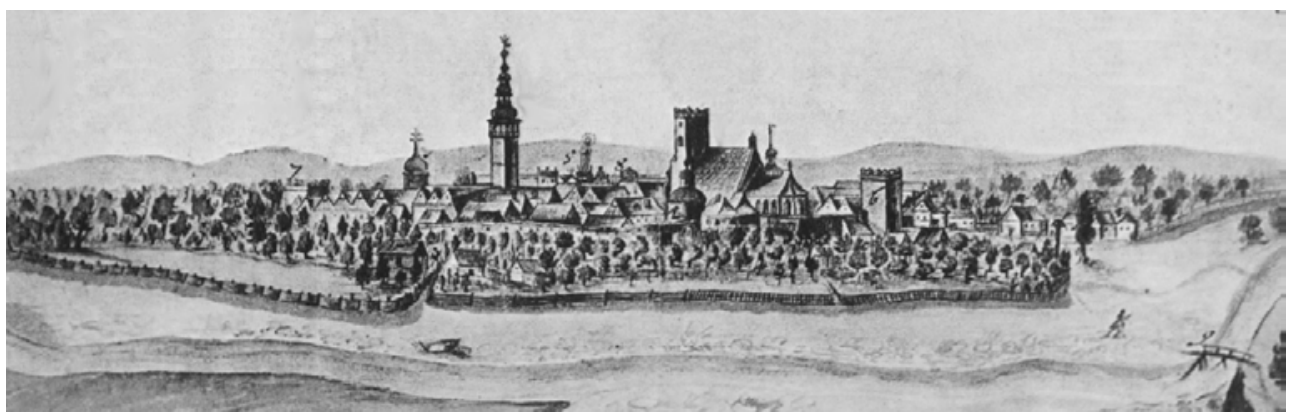

Figure 1: Moravská Ostrava in 1728. (Source: Archives of the City of Ostrava.)

In this context, Babel is an absolutely apt designation for Ostrava ("Moravian Klondike") and its history in the past two centuries. An unrestrained growth, haphazard plunder of natural resources, contamination of water, earth and air in striving for profits, mixing of Czech, German and Polish ethnic influences in the 19th century, coexistence of enthusiastic builders, political prisoners, gold-diggers, as well as real criminals in building the heavy industry in the 1950s. All of these are integral aspects of Ostrava and its present identity.

When we think of a common city, we see streets, houses, a park here and there. When we see Ostrava, then we first see only sandstones, mudstones and coal beds. It is a mass of rock, a huge sandwich of seventy coal cycles. Flames blaze like over a black kerosene lamp and heavy machines move over these. Only then can one see people and their homes, taprooms and shops. Ostrava is charged with energy, a city like a dragon and rock eater absorbing coal and creating flames in accord with red and black colours ... A crisis comes periodically and cuts the dragon's heads off. Dweeb the Dragon then regenerates somewhere in the corner for years as a lizard that has lost his tail. In between, people drink, gamble and, from what people elsewhere would consider a chronic form of hopelessness, they create a special freedom of rough cheeriness. Happily, no similar city - a well-built, provocative, dancing black woman with one poked out, pink eye - does not exist in this country. One Ostrava is enough, for both beauty and despair [2].

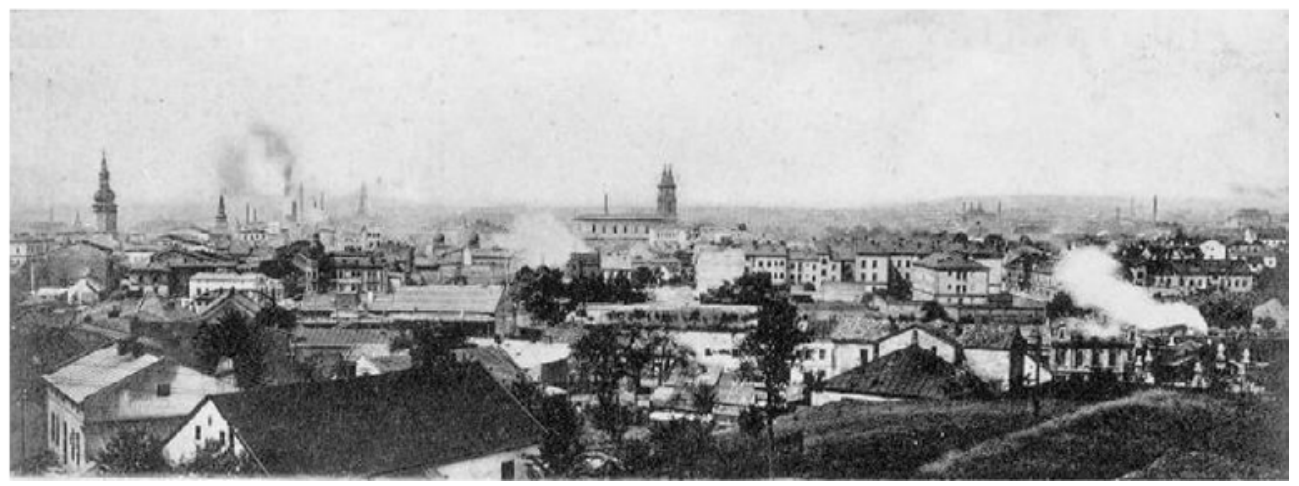

Figure 2: Ostrava in 1905. (Source: Archives of the City of Ostrava.) 


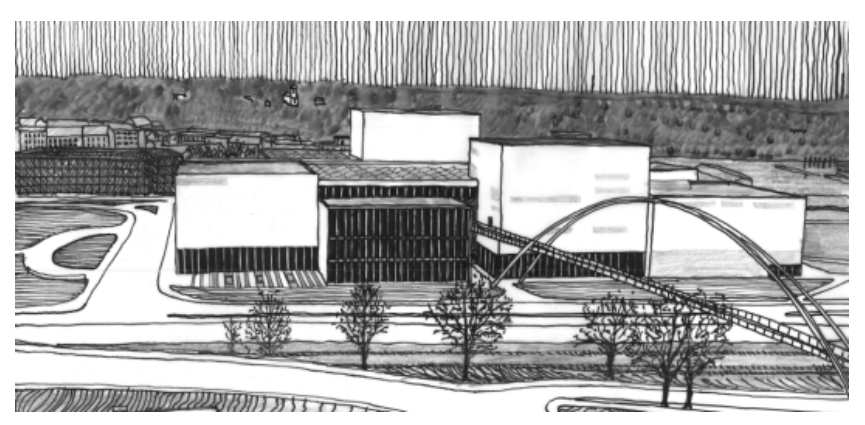

Figure 3: Panorama of Ostrava in 2017 - Shopping mall Nová Karolina. (Drawing: M. Nedvěd.)

The city was not prepared sufficiently for this change, though it could have been predicted that it would happen. This is proven by the dismal situation of brown fields, socially excluded localities, the languishing urban structure of the city and the spreading development with houses stretching over the city outskirts. Such a situation has arisen in which it is necessary to cope with not only the social-economic issue, but also the urbanistic one. Post-industrial localities gape with emptiness and languish or they are grasped in an unsuitable way. Individual urban units of which the city is composed were not able to unite in the coal boom period and it is still apparent at sight and feeling that they will not manage it in the near future. The public space framework is mushy, unreadable. It seems as if the interventions in the urban structure were not controlled.

But what will further happen with Ostrava? The city layout conception often changes, goals are not clear, unemployment grows, people migrate, the social composition changes, the settlement structure is fragmented and often not grasped or grasped badly. And processes are taking place in the city. They take place continuously. And these processes make cities living organisms. The processes take place naturally, the city creators try to guide them, which is their role for that matter. However, how much guidance is really necessary? This research deals with methods of how to guide the city according to natural processes dependent on cultural and historical factors. Will to live, vital forces, cultural and historical significance are sought. Because this is the way of finding places with a vitality potential. It is appropriate to put energy in such spaces and to support their development.

\section{SUSTAINABILITY RESEARCH METHODOLOGY BASED ON VITALITY}

\subsection{City structure and borders}

Ostrava comprises twenty-three municipal districts. Historically, the development of individual districts was different, which, in some cases, can be recognized from the urban structure even today. The historical core of the city is situated in the districts of Moravská Ostrava and Př́voz from where it spread to Vítkovice (ironworks and workers' settlement) and Mariánské Hory in the urban establishment of which also Camillo Sitte participated (as well as in Př́voz and now extinct Hrušov). Slezská (formerly Polská) Ostrava, most affected by coal mining and its remnants (heaps, shafts, settlements) became part of big Ostrava as late as 1939. The heavy industry from Vítkovice most expanded to Bartovice. Large housing estates Poruba and Ostrava-Jih were built after the Second World War and they were established in diametrically opposite ways - the block development of Poruba versus the 
modernistic housing estate structure of Ostrava-Jih. This conglomerate connects several smaller municipal districts with many caesuras made up of fields, meadows and alluvial forests and it surrounds a ring of satellites of rural or suburban character.

The borders of individual municipal districts usually do not correspond to the borders of the urbanized city structure. Finding these borders is important. It is only the determination of the borders of the urbanized city structure that shows where the city is situated, where the country and where the others are situated.

\subsection{System}

In this research was necessary to find, name, define and apply the System using which the current processes taking place in the city could be assessed. The result was called Sustainability Assessment System Based on Vitality. In order to effectively use the System, it was necessary to specify where the current borders of the city were (not administrative, but actual borders). These bordered municipal districts were then the subject of research. The first rating factor was the symbolic structure framework and the other rating factor for the research was vitality or, in other words, "appetite for life" (measured by many criteria: realty prices, occupancy of apartments, transportation, parking, civic amenities). It is these figures - borders, vital spaces, symbolic structure framework - that are the basis for creating the Sustainability Assessment System.

\subsubsection{Symbolic structure framework}

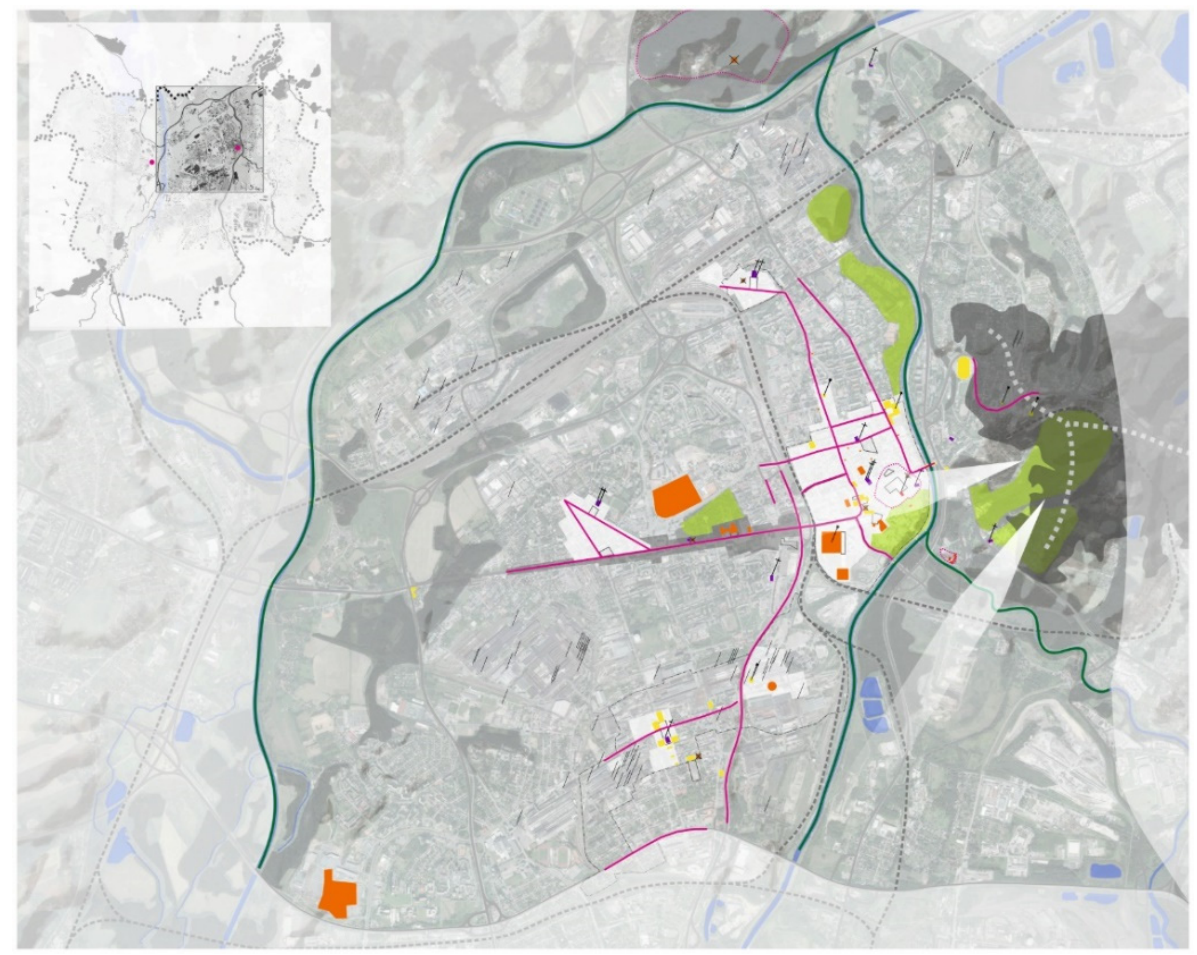

Figure 4: Symbolic structure framework in the centre of Ostrava. (Author: M. Mlčochová.) 
Finding the so-called symbolic structure framework relies on evaluation of municipal districts, spaces, places or buildings in relation to what their influence is for creating the cultural network in the city. They are simply elements with significant historical, social, cultural, economic or symbolic values. A number of elements fall into several categories with which they, however, strengthen their significant position in the city. However, unlike other major cities, Ostrava has a sparse and unstable symbolic structure framework. This is no wonder: before finding coal and spreading industrial activities, it was a mere cluster of several villages or small urban structures. Much was built during the industrial revolution, but now that we face industrial decline and its consequences, we stand before the question of what to do with the redundant post-industrial structure. The cultural expression of the industrial period has the same significance and value as the expression of any other period. The industrial period accented work and manufacture because society was focused on it. Life materialization and the application of rational discoveries spread quickly and reflected the current state of mind; therefore, it undoubtedly falls to our heritage.

The symbolic structure framework is constructed from buildings and spaces. Buildings and spaces are divided into natural and cultural ones. Both natural and cultural spaces can be of dot, line or area type. Natural and cultural buildings can be solitaire or group ones.

Buildings and spaces are rated by their significance - historical, cultural, social and symbolic.

Both buildings and spaces can be rated according to the table and the corresponding significance for the city can be assigned to them. With this initial rating, it is possible to obtain a comprehensive overview of ratings of specific buildings and spaces of the city. The rating can be burdened by the subjective view of the evaluator.

Examples:

Landek: The historically most significant area in Ostrava, Landek hill (a spatial natural and generally cultural element, historically and culturally significant - see Fig. 6) is situated to the north at the confluence of the Odra and the Ostravice, on an elevated spot in the area where the Odra flows towards Poland from the confluence through a narrow neck, at the place where the Bohemian Massif ends. Mammoth hunters lived there and were the first ones who used black coal as a fuel. The Venus of Petřkovice was found there. Landek is rightfully considered the birthplace of the local settlement.

Moravská Ostrava: Another historically significant and a city-creating, purely cultural space is then the core of Moravská Ostrava (general cultural space, historically and culturally significant). The settlement was created there near the ford across the Ostravice. Historically, the urban space developed in dependence on social conditions in the city. It has been preserved as the Centre of Ostrava in the inhabitants' minds up to today.

From the historical and cultural points of view, these two spaces are the most substantial for the symbolic structure framework. Their significance for the city is indisputable, which is also the reason why the symbolic structure framework should be stabilized there.

Others:

Buildings which also have a historical and also cultural importance can include, for example, churches, houses of prayer, town halls, and theatres. Spaces with a historical and/or cultural significance, generally cultural, are, for example, squares. Line cultural spaces are, for example, streets, promenades, boulevards, city avenues. Embankments then fall into line cultural and/or natural spaces. General natural spaces are parks and significant natural units.

In its substance, each building or space is unique. The reason why it is necessary to assess individual spaces and elements is that we could find those among the unique buildings and spaces that really create the symbolic structure framework and have the potential to stabilize it and contribute to its systematic development. 


\subsection{Vitality}

Vitality or appetite for life is the second rating factor in the Sustainability Assessment System. Vitality assessment is dependent on data obtained from demographic analyses, as well as on the rate of subjectivity put in the assessment.

Vitality in this passage means a determination of spaces where "something happens".

Spaces where vitality is concentrated can be considered suitable for regeneration, stabilization or development. Finding corridors between these spaces is of equal importance, because their isolation could become a problematic factor. Monitoring of the vitality of spaces and their concentration is very substantial for the development of the city. Therefore, it was vitality that was determined as one of the rating factors on which the Sustainability Assessment System is fundamentally dependent.

Vitality monitoring is the way with which it is possible to find spaces which inhabitants like or dislike to live in, spaces which inhabitants only pass through, spaces which, though in the city, have little in common with city-creating.

Vitality seeking: Nature - natural elements, forests, greenery, bio-corridors, rivers and the spaces surrounding them - it is possible to state with certainty that vitality is in all of these places. It is appropriate to determine and protect these spaces and to allow that they can be passed through.

The density of population, migration balance, the largest concentrations of population and the distribution of the number of flats - this data give an image of the city inhabitants.

Villages, suburbs - the manner of the last few decades, when inhabitants move to the outskirts of the city and thus these municipal districts become more and more vital at the expense of vitality in the inner districts of the city.

Roma settlements - also their vitality is very high; from the view of inhabitants they are often problematic localities, but it should be realized that it is the Roma community that uses public space most.

Students and young people - vitality is usually high where students concentrate. And there the hope for the city is being born - young blood which has the potential to be the future permanent population.

Popularity of city localities - this is a subjective factor, but significantly showing how vitality is seen by the city's inhabitants themselves.

\subsubsection{Sustainability assessment system}

As such, the assessment of vitality in the city would not have a sufficiently predicative function on which spaces should be stabilized and developed. The determination of buildings and spaces of the symbolic structure framework would also undertake only an informative function. However, if both rating factors are used simultaneously, it is possible to assess the spaces using this Sustainability Assessment System very effectively. The larger the vitality and the stronger the symbolic structure framework, the better position the space has within the whole.

\subsection{Results}

Borders of urbanized structures were determined in the fragmented structure of the city of Ostrava. Vitality was analyzed and the symbolic structure framework was defined in these spaces. These factors allowed us to rate the city from the view of the Sustainability Assessment System. The rating matrix (Fig. 8) is divided into six parts. The vitality and 


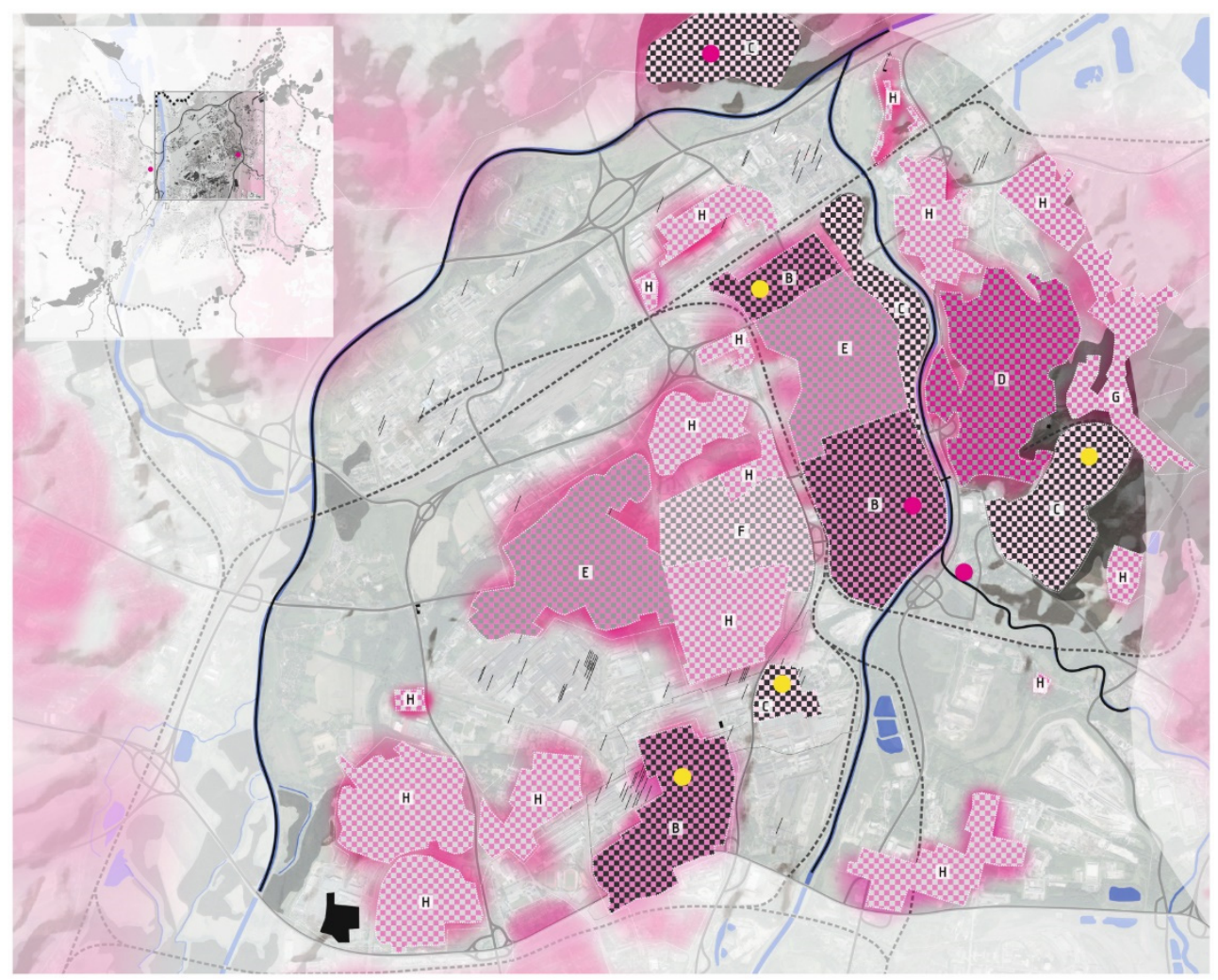

Figure 5: Sustainability Assessment System in the centre of Ostrava. (Author: M. Mlčochová.)

symbolic structure axes are divided into levels - weak, medium, strong. Thanks to the System's matrix it is thus possible to find spaces which are sustainable best - those which should be stabilized and developed, those in which it is useful to invest in and not let them languish. Spaces which are sustainable badly - it is not useful to invest an abundance of energy in them and to keep them alive by force, against natural processes taking place in them and also spaces which are in the middle of the matrix - in these it is necessary to determine their strengths and to further strengthen them so that in the future they could move to that part of the matrix with strong potential.

Example: To be able to connect the three largest urban units of Ostrava (Moravsko-Slezská Ostrava, Vítkovice with Ostrava-Jih and Ostrava-Poruba), it would be necessary to define (build up, grasp) spaces with an area larger than $15 \mathrm{~km} 2$, which - to achieve a sustainable density of population - would mean bringing there at least another 200,000 people who would help make the fragmented development denser and who would contribute with their taxes to the city operation. The distance between Poruba and Hulváky is over 2 kilometres. Poruba was built as Nová Ostrava, i.e. an independent city. It has appeared in this way to today and it is a functional urbanistic unit without the need of direct connection by an urbanistic framework with the rest of the city (specifically with Hulváky). The space that separates Moravská Ostrava from Vítkovice is also extremely vast. In the widest point, it is $1.5 \mathrm{~km}$ and 


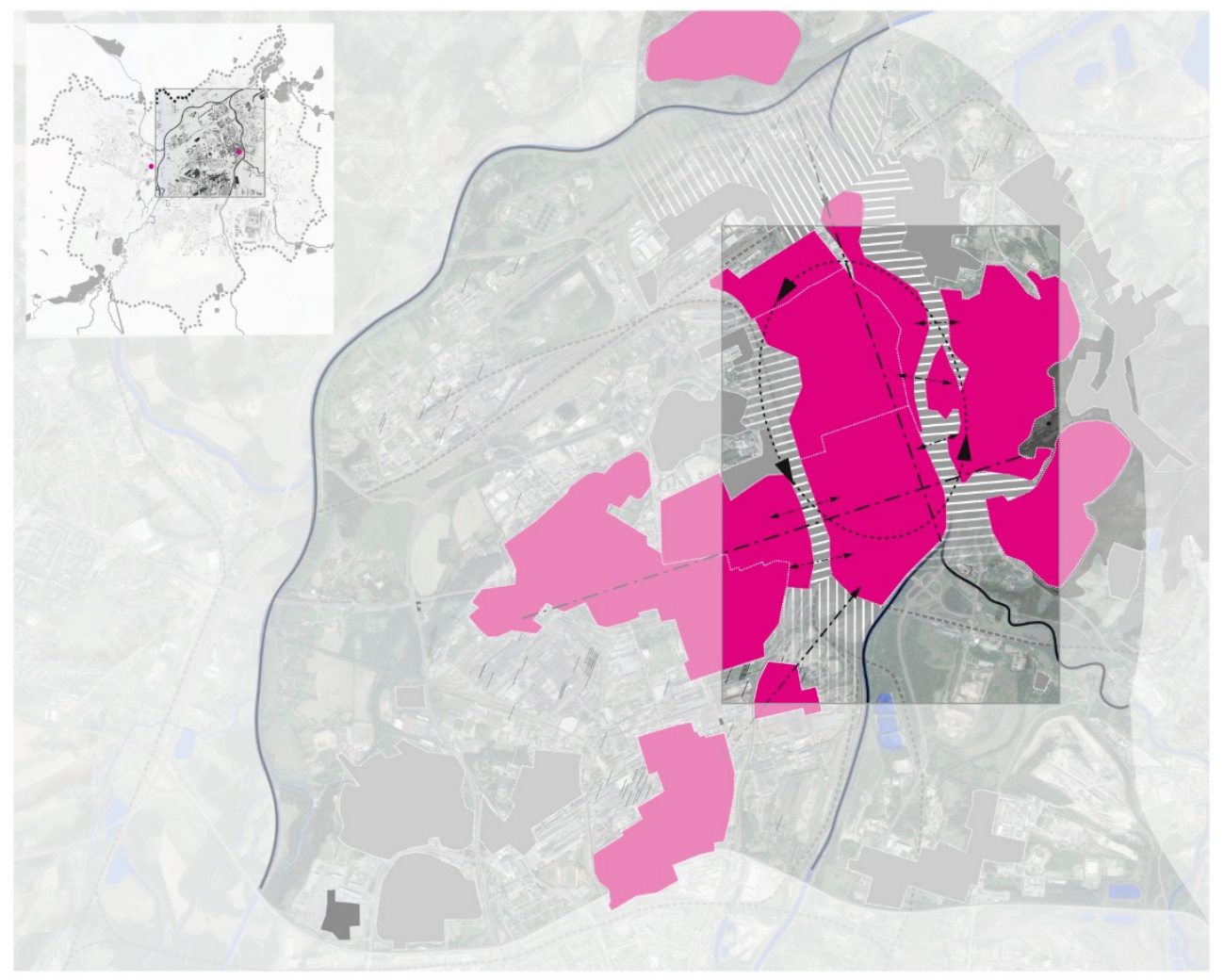

Figure 6: Results of Sustainability Assessment System in the centre of Ostrava. (Author: $M$. Mlčochová.)

is damaged by industrial activities (contamination, brownfields). Within the Sustainability Assessment System, investments in this space do not appear to be useful, conversely, they are shown to be investments against the natural life in the city, even in spite of the fact that much more energy is put there than, for example, in spaces which are potentially much more natural and suitable for stabilization - for example, in the space along the railway line dividing Moravská Ostrava into two territorial units, or in the space along the Ostravice which is the dividing element between Moravská Ostrava and Slezská Ostrava. The benefit of determination using the Sustainability Assessment System is exactly in assessing such disputable urban spaces.

\section{CONCLUSION}

Today's Ostrava is situated on an area of $214 \mathrm{~km}^{2}$; it is suffering from a rapid loss of job positions, negative migration and, despite stagnation of the heavy industry, also from the most polluted air in the country. The islands of settlements of urban type are divided there by long distances (forests, factories, strange areas of no man's land) and to cover them increases the intensity of motor traffic and thus also pollution. The present average density of population in Ostrava is 1,384 per square kilometre - just to compare; the density of population in Prague (Czech Capital City) is 2,600 per square kilometre. This means that 1,216 more people contribute with their taxes to the maintenance of one square kilometre of 
Prague infrastructure (in addition, with an income $42 \%$ higher on average). With the bloated structure of four-lane roads and multilevel intersections, which are popular in Ostrava planners mentally stuck in the 1970s, a relatively quality and dense network of mass urban transportation, the need to provide lighting everywhere and at least elementary security, this situation is unsustainable in the long term. (Data source: Czech Statistical Office, Population, Housing and Flat Census 2011.)

What are then the possible variants of the future development?

\subsection{Fragmentation}

Ostrava is already fragmented, but still it makes up one political and administrative unit (city). However, some of the municipal districts realize the unsustainability of the current state and the fact how they lose money on redistribution of the income on taxes of its inhabitants for the entire city. For instance, the municipal district of Poruba considers what would bring to it if it broke away from the Statutory City of Ostrava. As a relatively compact city with a developed infrastructure, a university (VŠB-TU) and a population of 70,000 with (in relation to Ostrava) slightly above-average incomes, it probably suffers from the nonhomogenous conglomerate making up the rest of the city and it would improve its financial position by becoming independent. If, when breaking away, it united with Svinov, it would also gain a significant traffic junction and would become a sustainable city with relatively clean air (the west limit of the agglomeration), a lot of greenery, as well as recreational opportunities. For future trouble-free functioning, it would have to invest in a new town hall and to build cultural institutions (libraries, galleries, theatres, cinemas), but basically it would gain a lot by becoming independent.

Poruba would be probably followed by rural (Pustkovec, Plesná, Krásné Pole, Petřkovice, Hošt'álkovice,...) or suburban (Polanka nad Odrou) satellites which can function without problems as independent municipalities.

However, the division would have a serious impact on the economically weaker municipal districts of Ostrava-Jih, Mariánské Hory and Hulváky, Slezská Ostrava and probably also on the historical core alone - Moravská Ostrava and Př́ivoz. These districts with socially excluded localities would probably suffer from decline, social tension and the growth of (already today high) criminality. If politicians resisted the temptation of financing various rescue packages aimed at social peace (which would disappear ineffectively in black holes and on the accounts of local mafia bosses), these localities (or their unsustainable parts) would gradually become depopulated and would remain to nature.

If Ostrava does not find sufficient force and energy for its further sustainable existence, such a curative process is perhaps the best possible solution.

\subsection{New coal}

On the contrary, in the European cities that are best rated in relation to the quality of life, sustainability and competitiveness (e.g. Vienna, Zurich, Stockholm, Copenhagen, etc.), 80$85 \%$ of job positions are made up of the tertiary (business, services) or quaternary (science and research) economic sector [3].

Relatively low costs of living, genius loci, the presence of a university and research institutes (nanotechnology centre, Anselm and Salamon supercomputers, etc.) or the advantageous position in the middle of Europe with good transport services could potentially attract companies dealing with information technologies, development centres or administrative headquarters with low and middle managements of large international 
companies. This market segment could then be a new "coal" - a fuel and energy for the city to survive. Dozens of other, less qualified job positions are related to it, which could help solve unemployment in the region. However, it will not come to the city on its own, nor can it be attracted by primitive incentives such as an industrial zone or a new motorway slip road, which apply to heavy industry. The idea of former mayor Kajnar that thousands of highly qualified and well-paid IT specialists or researchers will arrive in Ostrava every year after building a science and technology park with a growing capacity of thousands of workplaces a year is naive3. Well-educated, cultivated people who can work anywhere in the world will not voluntarily choose Ostrava to live if they do not have their quality cultural, social and sport enjoyments, good educational institutions for children, functioning services and opportunities of rest and short-term recreation in the city or in its close surroundings. Yet, the city still relentlessly resists investments in culture and quality, which is partly understandable - to justify hundred-million investments in a concert hall or library in a poor region with a high unemployment rate requires great political courage and the ability to persuade voters that such projects make sense and have the same or better economic return than building industrial zones for production lines and unskilled workers.

\section{RECOMMENDATIONS FOR OSTRAVA}

In 2010, an initiative of young architects and urban designers of Ostrava (Průša, Vysloužil, Kotek in cooperation with Department of architecture on Faculty of Civil Engineering in Ostrava) was established; they came with a project called Revitalized Ostrava and defined a sort of Decalogue for the city:

$01 /$ Clear vision. The city is a living organism which needs to be well fed and looked after. To do this, it is necessary to have a clear procedure for such care and the way of fulfilling it. Therefore, a vision should be adopted defining a specific orientation of the development of the city, its structure and determination of rules which define this development for 50 to 100 years. The vision must be generally known and, in its substance, comprehensible.

02/ Turning the city towards itself. Gradual steps leading to stop the city from stretching to the surrounding landscape and orientating the development inside the city. In this way, concentrated, integral and variegated housing with a more effective transport service and accessibility will be created.

03/ Interconnecting. A new structure and the related life are slowly growing on the connecting lines of important and busy places (concentration of activities, historical and cultural centres, urban mass transportation junctions, parks, and the like) which are the main focuses of the urban structure.

04/ Multiplicity of functions. Targeted mingling of different functions - housing, services, administration, culture and recreation, results in keeping life in the city for 24 hours a day. By stopping certain places from depopulating it is possible to efficiently prevent creating unmaintained and unsafe places or even ghettos.

$05 /$ Increasing the density of population. By filling the vacant and unmaintained spaces with buildings the patchy urban structure will gradually be filled up. Quality urban structure ensures a consistent separation of public and private spaces. A decrease in spaces administered by the city will result in increasing their quality and, conversely, determination and extension of private spaces will allow their users to make better use of them. A denser urban structure contains more variegated services and activities and it allows using roads and networks more effectively.

06/ Quality public spaces. A quality public space (a square, park or street), in particular, has the size adequate to its significance, it is clearly determined and well-arranged. It can be 
then built with appropriate care, easily maintained and guarded. People like to get together and they feel fine in such space.

07/ City for people. When building roads and pavements the principle should be that pedestrians move at one level - on the ground - in the urban parterre. This should prevent creating obstacles (barriers), easy movement of people about the city should be assured without unnecessary and unpleasant underpasses and bridges and the related easy accessibility from various places.

08/ Elimination of barriers and black holes. A barrier means an obstacle dividing a territory and interrupting the live flow in it. A black hole is a place which sucks energy and potential out of its surroundings. It attacks the living organism of the city like a malignant tumour. Lifeless, non-cultural, economically weak and socially unstable areas appear around the barriers and black holes. It is necessary to stop building new barriers and to specifically solve the existing ones. This means, in particular, finding the way of their positive involvement into the urban structure. In the case of black holes, it is necessary to reveal the reasons why they have occurred, to reduce them and also to avoid them in the future.

09/ City house. A city house has various contents and is busy 24 hours a day. Shopping spaces and services are situated on the ground floor, on the floors above there are usually offices and the top floors are always intended for living. Functions and activities thus mingle in the very basic structural unit of the city - in the house. City houses are arranged into closed blocks where the quiet inner yards are sufficiently separated from busy streets. Localities with city houses are busy all day long and thus they are safe.

10/ Conversions rather than demolitions means the conversion and revitalization of existing buildings, not only of industrial heritage, and their use for new purposes. In the case of unused buildings their new use should be preferred to structurally easier demolitions. There will be fewer incomplete investment goals and the face and memory of the city will be richer. This, however, need not always mean a return to the original form.

\section{ACKNOWLEDGEMENTS}

Work on the contribution was supported by the conceptual development of science, research and innovation for 2017 allocated to VSB-TUO by Ministry of Education, Youth and Sports.

\section{REFERENCES}

[1] Collective. Ostrava - Historie, kultura, lidé. 1st ed. Praha: NLN, 2013.

[2] Collective. Bílá kniha ostravské kultury. Ostrava: OIS, 2009.

[3] Stejskalová, L., Myslet město. 1st ed. Praha, VŠUP, 2014.

[4] Batty, M., The Size and Shape of Cities. Science, Nr. 319, pp. 769-771, 2008. 